\title{
The effect of solution-focused counseling on violence rate and quality of life of pregnant women at risk of domestic violence: a randomized controlled trial
}

\author{
Sepideh Dinmohammadi ${ }^{1}$, Mohsen Dadashi ${ }^{2}$, Elahe Ahmadnia ${ }^{1}$, Leila Janani ${ }^{3}$ and Roghieh Kharaghani ${ }^{1 *}$ (D)
}

\begin{abstract}
Background: Domestic violence during pregnancy as one of the most common social problems and major challenges of health systems can affect the health of the mother and fetus. The study aimed to compare the two groups of intervention based on solution-focused counseling and control in terms of violence and quality of life amounts in women who had experienced domestic violence.
\end{abstract}

Methods: A randomized controlled trial on 90 pregnant women was blocked into two intervention groups $(n=45)$ and a control $(n=45)$. The intervention group received six counseling sessions with a solution-focused approach. Study tool included conflict tactics scale (CTS-2) and short form health survey (SF-36). The tools were completed once before the intervention and again 6 weeks after the end of the counseling sessions by the participants of both groups. The $P$-value less than 0.05 was considered statistically significant.

Results: A total of 82/90 pregnant women were analyzed. The results showed that median and interquartile range (IQR) of physical, psychological and sexual violence significantly decreased in the intervention group than the control group ( $P s=0.001$ ). Moreover, quality of life scores significantly improved in the intervention group compared to the control group $(P=0.001)$.

Conclusion: Solution-focused counseling could be an effective approach to reduce the amount of violence and increase the quality of life in women exposed to domestic violence.

Trial registration: Iranian Registry of Clinical Trials IRCT2017040628352N4. Date of registration: August 20th 2017.

Keywords: Domestic violence, Solution-focused counseling, Quality of life, Pregnancy

\section{Background}

According to the estimates published by World Health Organization (WHO), 35\% of women worldwide are at risk of domestic violence and as many as $38 \%$ of women's homicides are committed by their spouses [1]. The incidence of domestic violence against pregnant women is

\footnotetext{
* Correspondence: r.kharaghani@yahoo.com

'Department of Midwifery, School of Nursing and Midwifery, Zanjan University of Medical Sciences, Zanjan, Iran

Full list of author information is available at the end of the article
}

reported to be $52 \%$ in Iran [2] and $28 \%$ in Zanjan [3]. Domestic violence can take many forms among which the physical, psychological, and sexual violence are the main types [4]. Violence is commonly used in controlling and domineering women [5] which could happen by causing physical aggression or even death threats, physical assaults, activity limitation, denying women's autonomy, and restricting women's access to life facilities [6], this in return could cause physical and psychological traumas which would result in developing low self-esteem, hatred

C C The Author(s). 2021 Open Access This article is licensed under a Creative Commons Attribution 4.0 International License, which permits use, sharing, adaptation, distribution and reproduction in any medium or format, as long as you give appropriate credit to the original author(s) and the source, provide a link to the Creative Commons licence, and indicate if changes were made. The images or other third party material in this article are included in the article's Creative Commons licence, unless indicated otherwise in a credit line to the material. If material is not included in the article's Creative Commons licence and your intended use is not permitted by statutory regulation or exceeds the permitted use, you will need to obtain permission directly from the copyright holder. To view a copy of this licence, visit http://creativecommons.org/licenses/by/4.0/. The Creative Commons Public Domain Dedication waiver (http://creativecommons.org/publicdomain/zero/1.0/) applies to the data made available in this article, unless otherwise stated in a credit line to the data. 
and fear from men $[6,7]$. Spousal violence specifically during pregnancy as an additional threat to the mother and fetus health not only cause serious physical disorder but also causes serious fetal consequences such as abortion, pre-mature delivery, low birth weight, and low Apgar score at birth [8-10].

The quality of life scale especially in mental health area in women who had experienced violence is decreasing, while rates for mental health problems such as depression, anxiety, insomnia, violence, and suicide are rising among these women. The reasons for the declining quality of life among women who had experienced violence is psychological trauma caused by deprivation of liberty, verbal and emotional abuse caused by continuous insults, disregarding women's emotions, social and economic inequalities, and doctorial actions of spouses, eventually would result in low confidence and self-esteem in women [11-13].

Empowering women plays a significant role in decreasing domestic violence which could consolidate the emotional bonds between couples [14, 15]; So, providing training and counseling sessions as an essential factor in this area is an important duty of health care workers [16]. Solution-focused brief counseling as one of the state-of-the- art and effective approaches in resolving marital problems was developed by a couple named Steve De Shazer and Insoo Kim Berg in Milwaukee brief family therapy center in Wisconsin, U.S.A., and is widely known as an ultra-modern brief therapy $[1,17]$. This approach helps clients find solutions to their problems, in addition to that; it helps them in identifying their capabilities in a way to become more hopeful about the future and create useful changes in their positions and perspectives in life $[18,19]$. The solution-focused approach claims that individuals are capable enough to promote the quality of their lives by creating appropriate solutions [20].

According to the searches conducted by researchers, there are no study on the effects of solution-focused approach on the quality of life in pregnant women who undergo violence in Iran or across the world. Thus, considering the high prevalence of violence, the harsh outcomes of violence during pregnancy and its impact on the quality of life of pregnant women, and due to the absence of similar studies conducted in Iran; the present study was conducted to determine the effects of solution-focused counseling on violence scale and the quality of life of pregnant women at risk of domestic violence.

\section{Methods}

\section{Trial design}

The study was a superiority parallel single-blind randomized controlled clinical trial with two groups of intervention and control in pregnant women at risk of domestic violence.

\section{Setting and participants}

The inclusion criteria comprised minor and medium levels of domestic violence in physical, psychological, and sexual subscales of the CTS- 2 in mothers, being over 18 years old, being less than or equivalent to 27 weeks of pregnancy based on Last Menstrual Period (LMP) or ultrasound results, literacy, living in the city of Zanjan, being married for at least a year, having no participation in any other classes or counseling courses simultaneously, having cell phones, absence of underlying illnesses, willingness to participate in counseling sessions and living together as a couple. The exclusion criteria included known psychological illness, psychoactive drug consumption, signs of addiction to drugs in pregnant women and their spouses, and being absent in more than one counseling sessions.

\section{Intervention}

The recruitment and the intervention were done in childbirth preparation class in a comprehensive urban health care center in Zanjan, Iran. At the time of the study the center had the only governmental childbirth preparation classes in the entire city. Pregnant women learn about pregnancy, childbirth and breastfeeding, and do exercise related to pregnancy in these classes. In the intervention group, counseling sessions based on solution-focused approach were held weekly for a period of 6 weeks in the form of 90- min. Counseling sessions were conducted individually and were held by the researcher. The themes in each session were as follows: the aims of the first counseling session include highlighting general principles of solution-focused counseling and providing proper definitions of problems to clients. The second session focused on the familiarity of participants with the concept of quality of life and solutionfocused approach. During the third session, clients learnt that there are different interpretations for an event and that they can develop the best interpretation in their minds while in the fourth session, clients were encouraged to discover exceptional opportunities of living as a couple. In the fifth session, with the help of miracle questions, participants were able to recognize their destructive behavior patterns. One of the main elements in this approach is the miracle questioning. This question actually encourages the person not to think about how and the chances of achieving the goals. Instead, the question arises as to what would occur to them if $\mathrm{mi}-$ raculous things happen, such as a miracle. This question helps people to have a very positive and different attitude towards their lives. With this question, one's mind shifts its focus from the cause of what is happening. 
Instead, the mind goes in a direction where the person has nothing as a problem. In the sixth session, a conclusion was made from the whole previous sessions to help the clients replace and experience their former thoughts and behaviors with the new ones. The control group received no intervention. In order to prevent the exchange of information between the participants of the two groups, the intervention group was explained that the exchange of information related to the counseling sessions between the intervention and control groups could distort the results. Also the sessions for this group of participants were held in a different place. Six weeks after the last counseling session, both groups were invited to complete the study tool for the second time. At this time the session was conducted in the presence of an interviewer who was completely unaware of the grouping procedure. To comply with ethical issues, after the questionnaires were completed at the follow-up period, the sessions were held for individuals in the control group who were willing to participate in these sessions.

\section{Study outcomes}

The outcomes of the present study included domestic violence and the quality of life in pregnant women who had been exposed to domestic violence which were measured and evaluated between the two intervention and control groups at 6 weeks follow ups.

\section{Sample size}

Based on previous study [21], the sample size was calculated for each group of 45 people with an error of $5 \%$ and a power of $80 \%$.

\section{Random allocation}

Participants were selected through a convenience sampling method and divided into two intervention (A) and control (B) groups using, quadruple random blocks. At first, all sequences of participants in each block was considered and then 23 blocks sequence was selected from random table number. The overall number of 90 pregnant women entered into the study from which 45 individuals were allocated to intervention and 45 individuals to the control group.

\section{Data collection tools}

Research tools for collecting data included demographic and reproductive checklist, CTS-2, and health-related quality of life questionnaire (SF-36); which were completed by qualified women. Demographic data included couple's age, couple's employment, couple's residential address and education status, marriage longevity, economic status, having cell phones, number of marriages and having children from the previous marriage.
Reproductive data related to pregnancy status included pregnancy duration, frequency of pregnancy and delivery, intended and unintended pregnancies, and infertility history. In order to identify whether pregnant women were at risk of domestic violence; CTS-2 was applied. The questionnaire is the newly revised version of the conflict tactics scale in addressing marital conflicts which was developed by Straus et el. (2007) with the confirmed Cranach's Alpha of 79\% for physical violence and $86 \%$ for psychological violence [22].

The applied questionnaire in the present study was validated by Ardabily et el. (2011) with the Cronbach's Alpha of $80 \%$ [23] which comprised 36 questions studying the conflict tactics on different dimensions of negotiation, physical, psychological, and sexual violence that leads to injuries. Although, the applied criteria in measuring the frequency and severity of violence in the CTS2 is considered to be from last year, according to the questionnaire designer, 1 year is predetermined and could be generalized to the desired time expected by the researchers [22]. Thus, in the questionnaire associated with the present study, instead measuring the previous year, 3 months' period was accounted for measurement. The SF-36 was applied for measuring the quality of life of participants, which included 36 questions and its validity in Iran has been verified by Montazeri et el. (2005) with the Cronbach's Alpha of 77 to $90 \%$. This tool evaluates the quality of life in two dimensions of physical and psychological health. Each dimension contains four subscales. Physical subscales include physical function, role limitation-physical health, bodily pain and general health and psychological dimension include vitality, psychological health, role limitation-emotional health, and social functioning [24].

\section{Statistical analysis}

The collected data were analyzed using SPSS V.16 and R statistical software. In order to study the normal distribution of variables, Kolmogorov- Smirnov test was applied. Categorical variables were examined using the Chi-Squared test and Fisher's exact test. In order to compare conflict tactics scale and the quality of life subscales between the two groups of intervention and control at baseline, independent t-test and Mann- Whitney $\mathrm{U}$ test were used. Since the residual distribution of variance between the two groups was not normal and there were no parametric covariance analysis (ANCOVA) assumptions, nonparametric ANCOVA was used to compare the variables between the two groups after the intervention. In this test, the outcomes are compared between the groups adjusted for the amount of baseline variables. Also, for comparing the conflict tactics scale, the quality of life, and their subscales between different phases of study, Wilcoxon and paired t-test were 
applied. The significance level of the aforementioned tests was based on $P$ value $<0.05$. The economic class was calculated considering factors such as house foundation, housing, and transportation means. In addition to that, for calculating social and economic levels, factors such as job ranking, education, and economic class were taken into consideration.

\section{Results}

\section{Participants}

Overall, 267 pregnant women completed the conflict tactic questionnaire. Of them 158 individuals had minor and medium levels of domestic violence based on conflict tactics scale (CTS-2) (the violence rate 59\%). Sixtyeight women did not meet the inclusion criteria. Therefore, 90 pregnant women entered into the study and randomly assigned to the intervention and control groups. In the intervention group four participants were excluded from the study, due to not attending the sessions $(n=4)$. Also, in the control group four participants were excluded due to unwillingness to continue the study. Eventually, the data from 82 pregnant women was analyzed. Figure 1 shows the flow diagram of the participants during the study. Others who had domestic violence but were not eligible or excluded from the study were referred to psychologist's offices.

\section{The preliminary analysis}

The mean (standard deviation) for women's age was 27.55 (5.13) in the intervention group and 27.26 (4.46) in control group, and as for men; the mean (SD) of the men's age was 31.44 (5.72) in the intervention group and 31.82 (4.72) in the control group. The mean (SD) for gestational age was 22.6 (2.35) in the intervention group and 22.73 (2.41) in control group. The majority of the participants socially and economically belonged to third class. The median of the gravidity in both groups was one. The two groups were similar with respect to age,

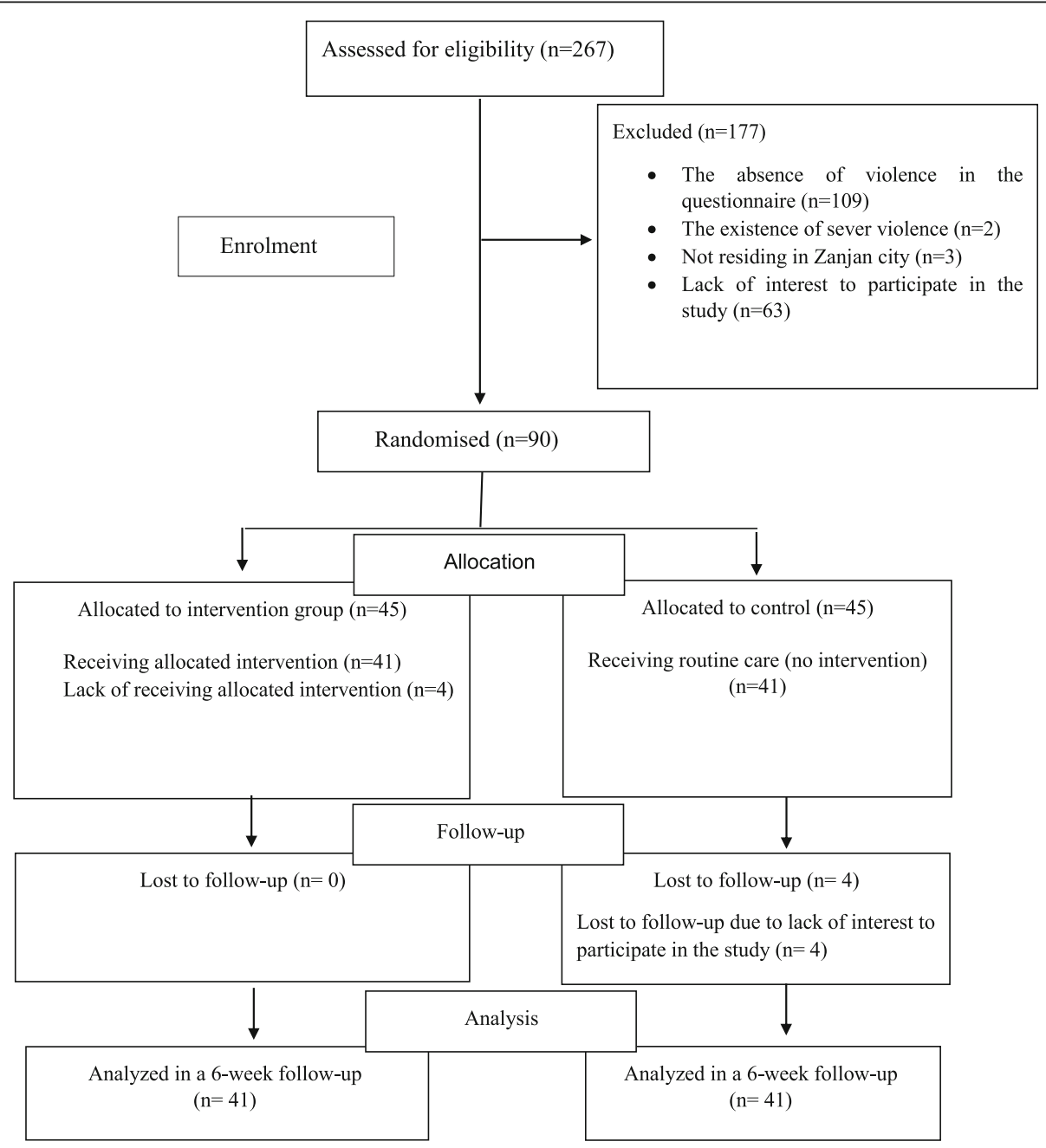

Fig. 1 The flowchart of sampling 
job, education, gestational age, parity, duration of marriage, wanting pregnancy, economic and social classes (Table 1).

\section{The intervention effects on violence}

The most observed violence in this study was associated with psychological violence. The median and interquartile range (IQR) of psychological violence was $0.375(0.62)$ in the intervention and $0.25(0.38)$ in the control group. Also, the median (IQR) of minor physical violence in both groups was $0(0.08)$. The groups were similar with respect to the conflict tactics subscales (Table 2).

The median (IQR) score of psychological violence in the intervention group had decreased dramatically from $0.375(0.62)$ at baseline to $0(0.25)$ at follow up. Also, the median (IQR) score of the minor physical violence subscale at 6 weeks follow-up in the intervention group was $0(0)$ which in comparison to the median baseline value of 0 (0.08), there was a statistically significant decreased. After matching the nonparametric ANCOVA test with the conflict tactics scale variables at the baseline; the results indicated that there was a significant difference between the two groups in negotiation $(P<0.001)$, physical violence $(P=0.001)$, psychological violence $(P=$ $0.001)$, and sexual violence $(P=0.001)$, however with regards to severe physical violence, no significant difference had been observed at the follow- up period (Table 2).

Table 1 Comparison of demographic and obstetric data in intervention and control groups

\begin{tabular}{|c|c|c|}
\hline \multirow[t]{2}{*}{ Variable } & Intervention $(n=45)$ & Control $(n=45)$ \\
\hline & Median (IQR) & Median (IQR) \\
\hline$\overline{\text { Woman's age (year) }{ }^{a}}$ & $27.55(5.13)$ & $27.26(4.46)$ \\
\hline Man's age (year) ${ }^{a}$ & $31.44(5.72)$ & $31.82(4.72)$ \\
\hline Female education (year) & $14(5.5)$ & $12(4)$ \\
\hline Male education (year) & $12(5)$ & $12(5)$ \\
\hline Duration of marriage (year) & $3(8)$ & $3(5)$ \\
\hline Woman's job (housekeeper) ${ }^{b}$ & $42(93.3)$ & $42(93.3)$ \\
\hline Previous marriage (yes) ${ }^{b}$ & $1(2.2)$ & $1(2.2)$ \\
\hline Child from previous marriage (no) ${ }^{b}$ & $45(100)$ & $45(100)$ \\
\hline \multicolumn{3}{|l|}{ Economic class ${ }^{\mathrm{b}}$} \\
\hline First & $8(17.8)$ & $12(26.7)$ \\
\hline Second & $17(37.8)$ & $10(22.2)$ \\
\hline Third & $12(31.1)$ & $14(26.7)$ \\
\hline Fourth & $7(15.6)$ & $8(17.8)$ \\
\hline Fifth & $1(2.2)$ & $1(2.2)$ \\
\hline \multicolumn{3}{|l|}{ Social class ${ }^{b}$} \\
\hline First & $5(11.1)$ & $6(13.3)$ \\
\hline Second & $14(31.1)$ & $12(26.7)$ \\
\hline Third & $19(42.2)$ & $18(40)$ \\
\hline Fourth & $6(13.3)$ & $9(20)$ \\
\hline Fifth & $1(2.2)$ & 0 \\
\hline Gestational age at enrollment (week) ${ }^{a}$ & $22.6(2.35)$ & $22.73(2.41)$ \\
\hline \multicolumn{3}{|l|}{ Wanting pregnancy ${ }^{b}$} \\
\hline Wanted & $12(26.7)$ & $15(33.3)$ \\
\hline Unplanned & $30(66.6)$ & $30(66.7)$ \\
\hline Unwanted & $3(6.7)$ & 0 \\
\hline Infertility history (yes) ${ }^{b}$ & $1(2.2)$ & $4(8.9)$ \\
\hline Gravidity & $1(1)$ & $1(1)$ \\
\hline Parity & $0(1)$ & $0(1)$ \\
\hline Duration of infertility (year) & 1 & 0 \\
\hline
\end{tabular}

${ }^{\mathrm{a}}$ Mean (standard deviation), ${ }^{\mathrm{b}}$ Numbers (\%) 
Table 2 Comparison of the subscales of conflict tactics scales between intervention and control groups at baseline

\begin{tabular}{llll}
\hline Variable & $\begin{array}{l}\text { Intervention }(\boldsymbol{n}=\mathbf{4 5}) \\
\text { Median (IQR) }\end{array}$ & $\begin{array}{l}\text { Control }(\boldsymbol{n = 4 5 )} \\
\text { Median (IQR) }\end{array}$ & $\begin{array}{l}\boldsymbol{p} \text { - } \\
\text { value }\end{array}$ \\
\hline Negotiation & $2.1(1.7)$ & $1.83(1.8)$ & 0.715 \\
Psychological abuse & $0.375(0.62)$ & $0.25(0.38)$ & $0.068^{\mathrm{b}}$ \\
Minor physical violence & $0(0.08)$ & $0(0.08)$ & $0.431^{\mathrm{b}}$ \\
Severe physical violence & $0(0)$ & $0(0)$ & $0.980^{\mathrm{b}}$ \\
Sexual abuse & $0(0.50)$ & $0(0)$ & $0.096^{\mathrm{b}}$ \\
\hline
\end{tabular}

Independent t test

${ }^{\mathrm{b}}$ Mann-Whitney U test

\section{The intervention effects on quality of life}

The baseline median (IQR) of the quality of life in the intervention group was 65 (27.8) and in the control group was 75.6 (22.5). The intervention group had reasonable lower quality of life scores than the control group at baseline. However, it wasn't statistically significant it may show that they were in worse situation than the control group. In the present study, the highest subscales scores were associated with physical functioning (The median (IQR) of the physical functioning in the intervention group was 80 (30) and in the control group was $85(20))$. The groups were similar with respect to the quality of life and its components (Table 3 ).
The median (IQR) of the quality of life at followup was $73.2(21.2)$ in the intervention group which indicated a statistically significant increase in comparison to the baseline value of 65 (27.8). However, there was a significant difference between the two groups with regards to total quality of life ( $p=$ $0.001)$, vitality $(p=0.003)$, psychological health $(p=$ $0.004)$, bodily pain $(p=0.014)$, physical functioning $(p=0.023)$, and social functioning $(p=0.019)$ at the follow- up period, however, there was no significant difference in other subscales of general health, role limitation-physical and role limitation-emotional health (Table 3).

Table 3 Comparison of quality of life and its sub-scales between two intervention and control groups during different phases of the study

\begin{tabular}{|c|c|c|c|c|}
\hline & \multirow[t]{2}{*}{ Variable } & \multirow{2}{*}{$\begin{array}{l}\text { Intervention } \\
\text { Median (IQR) }\end{array}$} & \multirow{2}{*}{$\begin{array}{l}\text { Control } \\
\text { Median (IQR) }\end{array}$} & \multirow{2}{*}{$\begin{array}{l}P \text { - } \\
\text { value }\end{array}$} \\
\hline & & & & \\
\hline \multirow[t]{9}{*}{ Baseline } & Quality of life & $65(27.8)$ & $75.6(22.5)$ & 0.052 \\
\hline & Vitality & $55(25)$ & $65(27.5)$ & 0.092 \\
\hline & Mental health & $68(26)$ & $72(28)$ & 0.184 \\
\hline & General health & $65(25)$ & $70(27.5)$ & 0.153 \\
\hline & Bodily pain & $67.5(20.8)$ & $67.5(32.5)$ & $0.227^{b}$ \\
\hline & Physical functioning & $80(30)$ & $80(20)$ & $0.188^{\mathrm{b}}$ \\
\hline & Role limitation-physical health & $75(62.5)$ & $100(25)$ & $0.146^{b}$ \\
\hline & Role limitation-emotional health & $66.55(100)$ & $66.66(66.66)$ & $0.126^{b}$ \\
\hline & Social functioning & $75(25)$ & $75(37.5)$ & $0.358^{b}$ \\
\hline \multirow[t]{9}{*}{ Follow-up } & Quality of life & $73.2(21.2)$ & $74(20.3)$ & $0.001^{c}$ \\
\hline & Vitality & $70(25)$ & $65(27.5)$ & $0.003^{c}$ \\
\hline & Mental health & $76(24)$ & $72(28)$ & $0.004^{c}$ \\
\hline & General health & $70(20)$ & $75(20)$ & $0.247^{c}$ \\
\hline & Bodily pain & $70.66(16.2)$ & $70.7(21.27)$ & $0.014^{c}$ \\
\hline & Physical functioning & $85(25)$ & $80(20)$ & $0.023^{c}$ \\
\hline & Role limitation-physical health & $75(50)$ & $75(50)$ & $0.134^{c}$ \\
\hline & Role limitation-emotional health & $66(67)$ & $100(77)$ & $0.541^{c}$ \\
\hline & Social functioning & $75(12.5)$ & $75(25)$ & $0.019^{c}$ \\
\hline
\end{tabular}

\footnotetext{
andependent $\mathrm{t}$ test

${ }^{b}$ Mann-Whitney U test

c Nonparametric ANCOVA
} 
In the intervention group, the changes of the conflict tactics subscales of negotiation $(p<0.001)$, physical violence $(p=0.039)$, psychological violence $(p<0.001)$, and sexual violence $(p<0.001)$ at follow-up phase versus baseline was statically significant. However, no statistically significant difference was recorded for severe physical violence.

Also, there were significant changes in quality of life subscales including general quality of life $(p<0.001)$, vitality $(p=0.002)$, psychological health $(p<0.001)$, general health $(p=0.003)$, role limitation-emotional health $(p=0.006)$, and social functioning $(p=0.045)$ at the follow-up period in comparison to baseline phase. However, there were no significant statistical differences in areas of bodily pain, physical functioning, and role limitation-physical health.

\section{Discussion}

The results of the study showed that, the rate of psychological, physical and sexual violence in the intervention group decreased compared to the control group. The basics of the solution-oriented approach are empowerment and increasing self-confidence. It seems that women, who underwent this type of counseling, found that they are able to find appropriate solutions to their problems and gained the ability to solve problems through positive negotiations with their spouses. Therefore, the amount of physical, psychological and sexual violence decreased. In the rate of severe physical violence, no statistically significant change was observed between the intervention and control groups in the followup. This was due to the fact that no new cases of this type of violence were observed in any of the participants of the intervention and control group. Since the followup period in this study was in the third trimester of pregnancy, it was possible that with increasing gestational age and increased risk of complications in the third trimester, spouses were less likely to commit this type of violence. The most common type of violence was psychological violence. This result was consistent with studies conducted in descriptive researches in Iran and the world [25-27]. The effect of counseling in reducing violence scores had indicated that raising awareness and empowering women would reduce the rate of violence [28]. In line with this research, other studies have also shown that cognitive counseling and anger management training are effective approaches to reduce domestic violence $[29,30]$.

The intervention group had reasonable lower quality of life scores than the control group at baseline. However, it wasn't statistically significant it may show that they were in worse situation than the control group. Align with the findings of the current research, other studies has shown that solution- focused counseling can increase the quality of life in women [20]. Furthermore, solution-focused counseling improves the quality of marital relationship between the couples and is effective on depression and satisfying about marital life [31, 32]. Also, conflict tactics counseling can lead to the reduction of marital conflicts between the couples [33]. The decline of violence rate and the increase of positive negotiations are two of the most likely reasons accounted for the increase of the quality of life in women who had undergone counseling and this has brought more emotional support from spouses.

The results of the current study indicated that the solution-focused approach can be an appropriate method to treat domestic violence and improve the quality of life dimensions in women who have experienced violence and are eligible for counseling.

\section{Strengths and limitations}

One of the main strengths of this study was the conduct of counseling intervention based on a new approach to controlling domestic violence against women. In which all the principles related to clinical trial studies such as one-sided blindness, random allocation and concealment of allocation were observed. The present study had some limitations. For example, because the questionnaires were completed on a self-report basis, it was likely that women did not respond correctly to the questionnaire for fear of revealing their private life issues. Therefore, to alleviate this concern, participants were given the necessary assurance that the information was confidential. Another limitation of the present study was the short follow-up period due to the limited time of pregnancy.

\section{Conclusion}

Solution-focused individual counseling has been found to be significantly effective in reducing domestic violence and increasing the quality of life in the intervention group and has led to improvements following negotiation and reduction in physical, psychological, and sexual violence. Also, the quality of life scores in other dimensions such as vitality, psychological health, bodily pain, physical and social functioning had been improved; however, still some domain of functioning such as the reduction of severe physical violence, improvement of general health components, role limitation-physical health and role limitation-emotional health remained unchanged. Due to the reduction of the majority of violence components and general quality of life; the implementation of this approach by healthcare institutions or other organizations in contact with women at risk of violence is approved to be beneficial. According to the results of the current study, there hasn't been a significant increase on the quality of life subscales such as general health, role limitation-physical health and role 
limitation-emotional health. It is better to use a larger and more diverse population for future studies whereby through extended follow-up periods; a thorough evaluation of counseling results would be possible. Also, it would be wise to have similar studies conducted on non-pregnant women.

\section{Abbreviations}

CTS-2: Conflict Tactics Scales; SF-36: Short Form health survey; LMP: Last Menstrual Period

\section{Supplementary Information}

The online version contains supplementary material available at https://doi. org/10.1186/s12884-021-03674-z.

\section{Additional file 1. Questionnaire.}

\section{Acknowledgments}

This study was part of the student's thesis with the registration code A-10980-9 whose protocol has been approved by the Ethics committee of Zanjan University of Medical Sciences (ZUMS.REC.1396.37) and was conducted with the financial support of Zanjan University of Medical Sciences. Hereby we would like to express our sincere gratitude and appreciation to the honorable deputy of the research university, the honorable president and colleagues of the comprehensive healthcare center three, especially dear midwives at the pregnancy preparation class, and pregnant women who participated in the study, for all their sincere guidance, coordination and cooperation in completing this research.

\section{Authors' contributions}

The first author SD has contributed in conceptualization, designing, collecting data, interpretation of data, writing this manuscript. MD has contributed in designing the study. EA participated in the designing and data collection. $L J$ participated in the designing and statistical analyses of the data. RKH designed and supervised all stages of the study, analyzed the data and revising drafts of this manuscript. All authors read and approved the final manuscript.

\section{Funding}

This research is supported by the Zanjan University of Medical Sciences. The funding body did not have any role in the study design, data analysis, manuscript preparation and submission.

\section{Availability of data and materials}

The dataset used in the present study is available from the corresponding author upon reasonable request.

\section{Declarations}

\section{Ethics approval and consent to participate}

All the required permissions have been obtained from Zanjan University of Medical Science with the registration code (ZUMS.REC.1396.37). From all mothers who were willing to participate a written informed consent was obtained.

\section{Consent for publication}

Not applicable.

\section{Competing interests}

The authors declare that they have no competing interests.

\section{Author details}

'Department of Midwifery, School of Nursing and Midwifery, Zanjan University of Medical Sciences, Zanjan, Iran. ${ }^{2}$ Department of Clinical Psychology, School of Medicine, Zanjan University of Medical Sciences, Zanjan, Iran. ${ }^{3}$ Department of Biostatistics, School of Public Health, Iran University of Medical Sciences, Tehran, Iran.
Received: 7 June 2020 Accepted: 25 February 2021

Published online: 20 March 2021

\section{References}

1. World Health Organization. Violence against women. Available online at: http://www.who.int/mediacentre/factsheets/fs239/en/. Accessed 29 Nov 2017

2. Soleimani A, Delpisheh A. Prevalence of violence against women in Iran: systematic review and Meta-analysis. J Urmia Nurs Midwif Faculty. 2016; 13(11):973-86

3. Shakerinezhad M. Domestic violence and related factors in pregnant women. J Zanjan Univ Med Sci. 2013;21(89):117-26.

4. World Health Organization. Violence against women. Fact sheet N 239. Updated 2016. Available online at: http://www.who.int/mediacentre/fa ctshee.

5. Hajnasiri H, Ghanei Gheshlagh R, Karami M, Taherpour M, Khatooni M. Physical, sexual and emotional violence among Iranian women: a systematic review and meta-analysis study. Sci J Kurdistan Univ Med Sci. 2017; (21): 110. t: https://www.researchgate.net/publication/313388703.

6. Niazi M, Kassani A, Menati R, Khammarnia M. The prevalence of domestic violence among pregnant women in Iran: a systematic review and metaanalysis. Sadra Med Sci J. 2015;3(2):139-50.

7. Danesh P, Sharbatian MH, Tavafi P. Sociological Analysis of Domestic Violence Against Women and its Relationship with feel safe at home (A Case Study of Women aged 18-54 in the Miyaneh). Strat Res Secu Soc Order. 2015:6(1):47-72

8. Kataoka $Y$, Imazeki M. Experiences of being screened for intimate partner violence during pregnancy: a qualitative study of women in Japan. BMC Womens Health. 2018;18(75):1-9 https://doi.org/10.1186/s12905-018-0566-4.

9. Golmakani N, Azmodeh E. Domestic violence in pregnancy, outcomes and strategies: a review article. Iran J Gynecol Infertil. 2013;15(42):13-22 http:// ijogi.mums.ac.ir/article_571.html.

10. Ghazanfarpour M, Khadivzadeh T, Rajab Dizavandi F, Kargarfard L, Shariati Kh, Saeidi M. The relationship between abuse during pregnancy and pregnancy outcome: an overview of Meta - analysis. Int J Pediatr 2018; 6 (10): 8399-8405. http://ijp.mums.ac.ir.

11. Dayana K, De LT, Cristina E, Oliveira T. Association between domestic violence and womens quality of life 1. 2017;25:e2901 1-8. http://10.1590/1 518-8345.1535.2901.

12. Asadi S, Mirghafourvand M, Yavarikia P, Mohammad-Alizadeh-Charandabi S, Nikan F. Domestic violence and its relationship with quality of life in Iranian women of reproductive age. J Fam Violence. 2017;32(4):453-60.

13. Ansari $H$, Golshiri P, Mostajaboldavati SR. The effect of women's communication skills on domestic violence. J Isfahan Med Sch. 2017;35(444): 1080-7 http://dx.doi.org.

14. Taghdisi MH, Latifi M, Afkari ME, Dastoorpour M. The impact of educational intervention to increase self efficacy and awareness for the prevention of domestic violence against women. Iran J Health Educ Promot. 2015;3(1):328 https://www.researchgate.net/publication/279183257.

15. Maleki G, Zabih Zadeh A, Panaghy L, Rashidi M. The conflict resolution tactics in various attachment styles of couples. J Thought Behav Clin Psychol 2014; 8 (31): 77-86.

16. Falb K, Olavarrieta C, Campos P, Valades J, Cardenas R. Evaluating a health care provider delivered intervention to reduce intimate partner violence and mitigate associated health risks: study protocol for a randomized controlled trial in Mexico City. BMC Public Health. 2014;14(772):1-10 http:// www.biomedcentral.com/1471-2458/14/772.

17. Milnera J, Singleton T. Domestic violence: solution-focused practice with men and women who are violent. J Fam Ther. 2008;30:29-53 https://doi. org/10.1111/j.1467-6427.2008.00414.x.

18. Davoodi Z, Etemadi O, Bahrami F. Short-term solution-focused approach to reduce the tendency to divorce the women and men prone to divorce. Quart J Soc Welfare. 2010;11(43):121-34

19. Shakarami M, Davarniya R, Zahrakar K. The effectiveness of solution-focused brief therapy (sfbt) on reducing marital stress in women. J llam Univ Med Sci. 2013;20:18-26

20. Mahmudi MJ, Sanai B, Nazari AM, Davarniya R, Bakhtiari Said B, Shakarami M The effectiveness of solution-focused brief therapy (SFBT) on reducing couple burnout and improvement of the quality of life of married women. Armaghane Danesh. 2015;20(5):416-32. 
21. Tafreshi M, Amiri Majd M, Jafari A. The effectiveness of anger management skills training on reduction family violence and recovery marital satisfaction. J Fam Res. 2013;9(3):299-310.

22. Straus MA. Conflict tactics scales. Encyclop Domestic Viol. 2007:44:190-7.

23. Ardabily HE, Moghadam ZB, Salsali M, Ramezanzadeh F, Nedjat S. Prevalence and risk factors for domestic violence against infertile women in an Iranian setting. Int J Gynaecol Obstet. 2011;112(1):15-7 https://doi.10. 1016/j.jigo.2010.07.030.

24. Montazeri A, Goshtasebi A, Vahdaninia M, Gandek B. The short form health survey (SF-36): translation and validation study of the Iranian version. Qual Life Res. 2005;5(1):49-56 https://doi.10.1007/s11136-004-1014-5.

25. Tavoli Z, Tavoli A, Amirpour R, Hosseini R. Quality of life in women who were exposed to domestic violence during pregnancy. BMC Pregnancy Child 2016; 16:19: 1-7. https://doi.10.1186/s12884-016-0810-6

26. Almeida F, Coutinho E, Duarte J, Chaves C, Nelas P. Domestic violence in pregnancy: prevalence and characteristics of the pregnant woman 2017; 26 (15-16): 2417-2425. https://doi.10.1111/jocn.13756

27. World Health Organization. Intimate partner violence. Underst Address Viol Against Women. 2012; 1-12. https://apps.who.int/iris/handle/10665/77432

28. Tiwari A, Leung WC, Leung TW, Humphreys J, Parker B. A randomised controlled trial of empowerment training for Chinese abused pregnant women in Hong Kong. Bjog-An Int J Obstet Gynacol. 2005;112:1249-56 https://doi.10.1111/j.1471-0528.2005.00709.x.

29. Kiely M, El-Mohandes A, El-Mohandes M, Gantz M. An integrated intervention to reduce intimate partner violence in pregnancy: a randomize trial. NIH Public Access Obstet Gynecol. 2010;115(2 Pt 1):273-83 https://doi. 10.1097/AOG.0b013e3181cbd482.

30. Naeem M, Aligolizadeh Moghadam S, Rezaei Sharif A, Ahari S. The Effectiveness of Anger Management Skills Training on Marital Adjustment and Reducing Domestic Violence Against Women in Ardabil. Ann Conf Res Human Soc Stud. 2017:1-11.

31. Monemiyan G, Khoshkonesh A, Poorebrahim T. Effectiveness of solutionfocused brief therapy on the reduction of couple burnout and optimizing the quality of marital relationship in married women. J Kashan Univ Med Sci. 2016;20(2):165-72 http://feyz.kaums.ac.ir/article-1-3029-en.html.

32. Abbasi A, Davarniya R, Mohammadi M, Babaiegarmkhani M. Effectiveness of solution- focused brief therapy (SFBT) on reducing depression and increaing marital satisfaction in married women. Iran J Nurs. 2017;30(105):34-46 URL: http://ijn.iums.ac.ir/article-1-2420-en.html.

33. Sudani M, Shafi Abadi A, Adammadi A. Comparison of the effectiveness of dyshizar decision-based therapy in individual and combined methods in reducing marital conflict. J Educ Psychol. 2010;5(14):39-54.

\section{Publisher's Note}

Springer Nature remains neutral with regard to jurisdictional claims in published maps and institutional affiliations.

Ready to submit your research? Choose BMC and benefit from:

- fast, convenient online submission

- thorough peer review by experienced researchers in your field

- rapid publication on acceptance

- support for research data, including large and complex data types

- gold Open Access which fosters wider collaboration and increased citations

- maximum visibility for your research: over $100 \mathrm{M}$ website views per year

At $\mathrm{BMC}$, research is always in progress.

Learn more biomedcentral.com/submissions 